\title{
Reflexiones sobre Patrimonio Cultural, aprendizaje y video juego
}

\author{
Reflections on Cultural Heritage, learning and video game
}

\author{
Jorge Andrés Palma Villalón \\ jorge.palma@alumnos.uda.cl \\ Código ORCID: 0000-0002-0701-7177 \\ Universidad de Atacama, Copiapó, Chile
}

\author{
Nahur Manuel Meléndez Araya \\ nahur.melendez@uda.cl \\ Código ORCID: 0000-0001-9414-9145 \\ Universidad de Atacama, Copiapó, Chile
}

| Artículo recibido en marzo 2021 | Arbitrado en abril 2021 | Aceptado en abril 2021 | Publicado en mayo 2021

\section{Resumen}

La educación tiene un papel muy importante en el desarrollo de procesos que promuevan el conocimiento del patrimonio cultural, de la región de Atacama, para desarrollar valores de pertenencia y cuidado en los estudiantes de educación básica. Esta investigación tiene como objetivo evaluar la efectividad del videojuego 2D“Rescue Heritage", diseñado para esta investigación, con el propósito de lograr un aprendizaje significativo del patrimonio cultural de Atacama. Es una investigación evaluativa y el diseño es de campo. La técnica de recolección de datos es la encuesta y el instrumento para medir los efectos del juego es un cuestionario estructurado. La población estuvo constituida por 15 estudiantes con edades comprendidas entre los 5 y 12 años. Se concluye que los videojuegos son efectivos para lograr aprendizajes de conocimientos de datos, hechos y nuevos conceptos relacionados con el patrimonio cultural de la región de Atacama.

\footnotetext{
Abstract

Education plays a very important role in the development of processes that promote knowledge of the cultural heritage of the Atacama region, to develop values of belonging and care in basic education students. This research aims to evaluate the effectiveness of the 2D video game "Rescue Heritage", designed for this research, with the purpose of achieving a meaningful learning of the cultural heritage of Atacama. It is an evaluative investigation; the design is from the field. The data collection technique is the survey and the instrument to measure the effects of the game is a structured questionnaire. The population consisted of 15 students aged between 5 and 12 years. It is concluded that video games are effective for learning about data knowledge, facts and new concepts related to the cultural heritage of the Atacama region.
}

\section{Palabras clave:}

Aprendizaje significativo, educación patrimonial, patrimonio cultural, diseño de videojuego educativo, videojuegos y aprendizaje

\section{Keywords:}

Meaningful learning, heritage education, cultural heritage, educational video game design, video games and learning 
INTRODUCCIÓN

El patrimonio cultural es un conjunto de bienes tangibles, intangibles naturales y artificiales que contiene información del entorno desde épocas pasadas y su evolución hasta el presente. El patrimonio forma parte de prácticas sociales que tienen significados $y$ valores los cuales se transmiten a través de las generaciones. Para la UNESCO (1982) es el legado que se recibe del pasado, que se vive en el presente y transmitimos a las generaciones futuras. Para Pagès-Pons, (1986) el patrimonio es la representación de lo que se ha denominado "el pasado que tenemos presente", en este mismo orden de ideas DIBAM (2005) resalta el dinamismo de lo que es o deja ser un patrimonio o bien cultural. ya que el colectivo es quien decide si desaparece o afirma su condición.
Es así como el valor de dichos bienes y manifestaciones culturales no está en un pasado rescatado de modo fiel, sino en la relación con la cual en el presente establecen las personas y las comunidades con estos significados.

No obstante de estar rodeados de fuentes patrimoniales en el contexto formal, éstas se utilizan poco como recursos y actividades para fomentar el interés y mejorar el conocimiento de los estudiantes. Por esta razón la educación del patrimonio cultural es de gran importancia porque a través de los procesos de enseñanza y aprendizaje se logra que las nuevas generaciones lo conozcan y valoren, al respecto Stearns, Seixas y Wineburg, (2000) e Ibáñez, Fontal y Cuenca (2015) coinciden en señalar que la educación patrimonial involucra la secuencia y relación de los elementos representados en la figura 1.

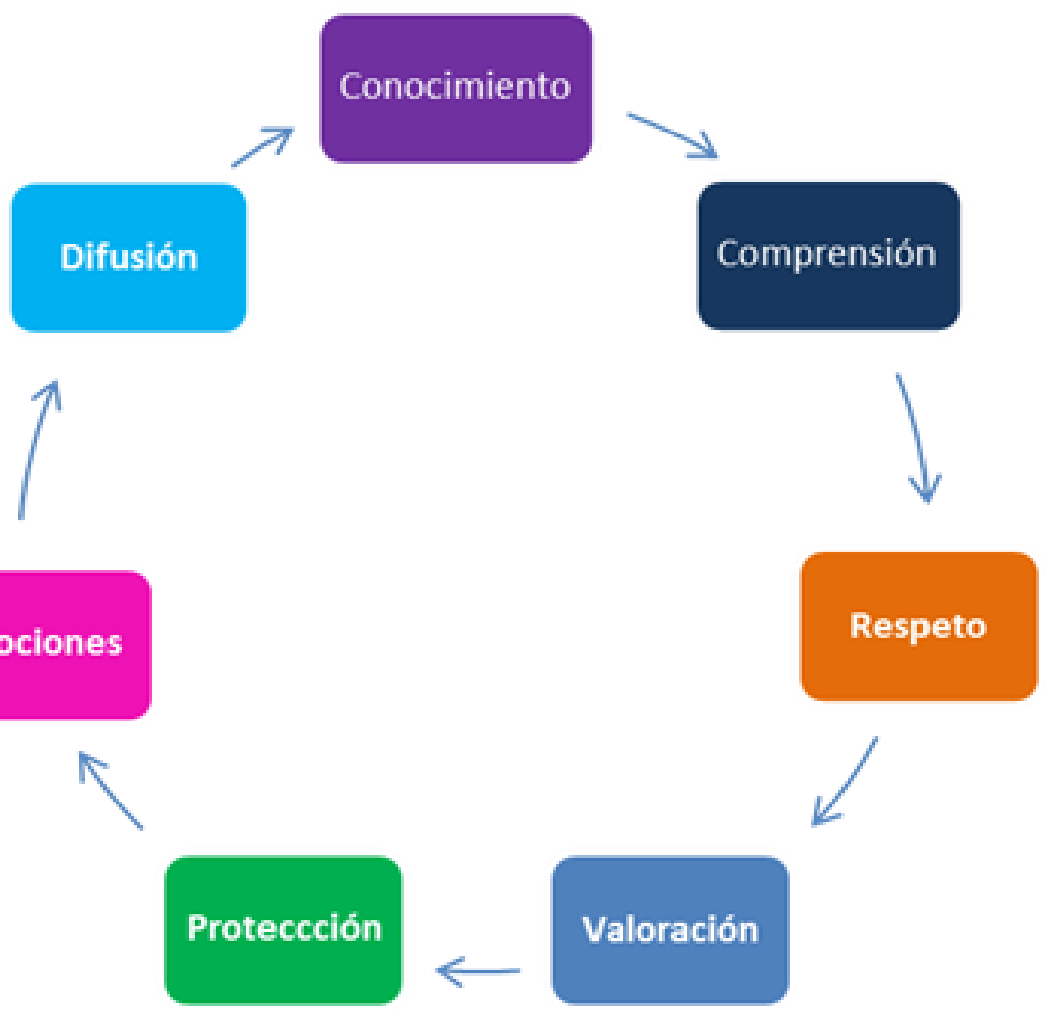

Figura 1. Relación de elementos de la educación patrimonial. 
El aprendizaje del patrimonio cultural genera el desarrollo del pensamiento crítico y reflexivo de la realidad, así como también, de la inteligencia emocional. Este conocimiento y su ubicación en el contexto temporo espacial permiten que el estudiante comprenda esa importancia y desarrolle valores de pertenencia y respeto con la región y su historia, también consigue vincular con las emociones y lograr que los individuos protejan, disfruten y promuevan su patrimonio.

Por esta razón la educación del patrimonio cultural tiene gran importancia a nivel mundial y local. En Chile para atender y fortalecer la educación de las artes, la cultura y el patrimonio, en estudiantes de educación básica, se crearon en el 2018 el Fondo de Fomento al Arte en la Educación (FAE) y los Fondos de Cultura en el 2020. Asimismo en el mes de mayo se celebra el "Día del Patrimonio Cultural de Chile" (DPC), la cual es una actividad anual coordinada por el Consejo de Monumentos Nacionales de Chile (CMN), cuya finalidad es permitir a la ciudadanía en general conocer y disfrutar del patrimonio cultural, histórico y arquitectónico nacional (Chile, Cultura, s.f.).

La región de Atacama cuenta con 22 inmuebles declarados monumentos históricos, además de una zona típica y dos santuarios de la naturaleza (Chile, leychile, 1925 y Unesco, 2011) En esta región se celebra el DPC con actividades como obras de teatro y artes visuales (cooperativa.cl, 2020). Sin embargo, en la actualidad por efectos de la pandemia del COVID-19, las actividades se realizaron de forma remota, a través de internet. Esta situación puso de manifiesto la necesidad de tener herramientas tecnológicas que promuevan el patrimonio y la cultura a nivel nacional.

Actualmente los estudiantes de educación básica, denominados "millennial", por sus condición de haber nacido en la era de la tecnología en el siglo XXI, se caracterizan por ser una generación digital, hiperconectados por el uso constante de la tecnología, al respecto Reig (2012) considera que para los ciudadanos de este siglo las Tecnologías de la Información (TIC), las tecnologías para el Aprendizaje y la comunicación (TAC) y las tecnologías para el Empoderamiento y la Participación (TEP) son herramientas básicas, por lo tanto la educación debe hacer uso de ellas para motivar y promover el aprendizaje significativo.

En el mundo de las tecnologías el videojuego es un recurso cada vez más frecuente en los procesos de enseñanza y aprendizaje como así lo confirman los estudios realizados por Cuenca y Martin (2010); Cheng \& Su, (2012); Sánchez y Esnaola (2014), Jiménez-Palacios y Cuenca (2015); estos autores concluyen que la tecnología puede convertirse en una gran herramienta para utilizar en las aulas, pues resulta atractiva para estudiantes y docentes; favorecen el aprendizaje y el rendimiento académico

Además los videojuegos han mostrado su potencial para el aprendizaje de la Historia y educar patrimonialmente como lo concluye Martínez Soto, Egea Vivancos y Arias Ferrer, (2018).

Los estudiantes se involucran y se motivan por el aprendizaje si consideran que los contenidos son útiles y relevantes, además la forma como se presentan los contenidos tiene gran importancia, si los estudiantes usan la tecnología con frecuencia entonces este puede ser un medio idóneo para la enseñanza. Los videojuegos pueden convertirse en una estrategia lúdica que permita generar situaciones educativas motivadoras y enriquecedoras para el aprendizaje del patrimonio cultural.

Por lo antes planteado en esta investigación se diseña el videojuego educativo denominado Rescue Heritage (RH), el cual se aplica a una muestra de estudiantes para evaluar su efectividad. La pregunta de investigación que se plantea es: ¿Cuál es la efectividad del videojuego Rescue Heritage (RH) para el logro de 
aprendizaje significativo acerca de los entornos patrimoniales culturales de la región de Atacama en estudiantes de educación básica?

Asimismo el objetivo que guía la investigación es: evaluar la efectividad del videojuego Rescue Heritage ( $\mathrm{RH}$ ) para el logro de aprendizaje significativo acerca de los entornos patrimoniales culturales de la región de Atacama en estudiantes de educación básica.

\section{MÉTODO}

Es una investigación evaluativa ya que se obtienen los resultados de la aplicación del videojuego $2 \mathrm{D}$, la población la conforman 15 estudiantes de diferentes instituciones de educación básica y pre-básica, con edades comprendidas entre 5 y 12 años. La aplicación del juego se realizó de forma remota por los requerimientos de distanciamiento debido a la pandemia por el COVID-19. La técnica de recolección de datos fue una encuesta y el instrumento un cuestionario de respuesta estructurada que permitió medir la percepción que tienen los participantes al culminar la experiencia jugable, el aporte al proceso de enseñanza-aprendizaje y aspectos de la constitución del juego RH.

En la Tabla 1 se resumen los elementos que constituyen el cuestionario.

Tabla 1. Elementos del cuestionario.

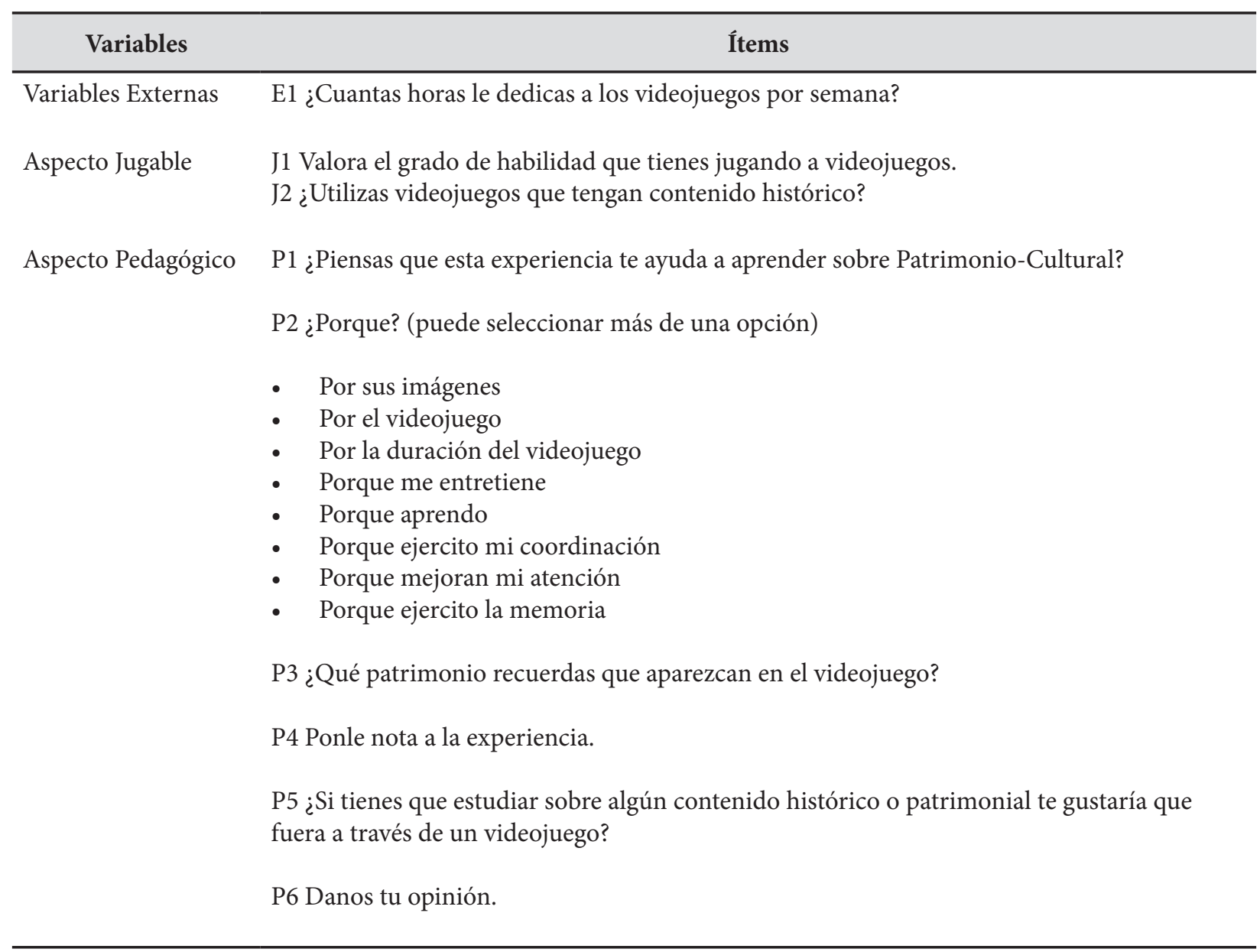




\section{Propuesta - Video juego}

El videojuego "Rescue Heritage" se diseña para facilitar el aprendizaje del patrimonio cultural de la región de Atacama en Chile, está concebido para niños de enseñanza básica y prebásica con edades comprendidas entre 5 y 12 años de edad.

\section{Diseño del videojuego "Rescue Heritage"}

Para el desarrollo del proyecto del videojuego se utilizó la metodología Waterfall (Cascada), con dos fases: preproducción y producción con sus distintas etapas de desarrollo. En primer lugar para la fase de preproducción se da a conocer el concepto del juego, en la siguiente fase de producción conformada por cuatro etapas: la I etapa el diseño de juego, la II etapa el diseño técnico, la III etapa la implementación y la IV etapa las pruebas.

\section{Fase de Preproducción}

Definición: El RH es un video juego de plataforma $2 \mathrm{D}$, el cual en su primera versión se desarrolla para el sistema operativo Android 4.4 en adelante. Este juego está constituido por lugares considerados patrimonio histórico cultural de la región de Atacama en Chile de acuerdo al Consejo de Monumentos Nacionales de Chile (s.f.) y a la UNESCO (2011). Los sitios representados en esta primera versión del juego son:

1. La estación de ferrocarril de Caldera: Se encuentra ubicada en la costanera Guillermo Wheelwright en la ciudad de Caldera, en la III Región de Atacama. Es uno de los puntos terminales de la primera vía férrea que se construyó en Chile.

2. La locomotora "La Copiapó": Es la más antigua que se conserva en Sudamérica. Pese a que la línea de ferrocarril en la que fue inaugurada, que iba desde Copiapó a Caldera, no es la más remota de América
Latina, la locomotora sí es la más antigua que se conserva. En la actualidad, la histórica locomotora se encuentra ubicada en los patios del Campus Paulino del Barrio en la Universidad de Atacama.

3. 3. Los acueductos de Amolanas: Fueron construido en 1890 por iniciativa de Agustín Edwards Ossandón y con el trabajo de obreros españoles especialmente contratados para la obra. El propósito de esta construcción era transportar agua desde el río Copiapó hasta una turbina que generaría energía eléctrica para el funcionamiento de la planta faenadora.

4. Las chimeneas de Labrar: Son vestigios de la antigua Fundición de Cobre de Labrar. Además de las dos chimeneas construidas en 1846, incluye las ruinas del poblado de Labrar y campos de escoria o restos de cobre de la fundición. Estas chimeneas donde se derretía el cobre son los únicos testimonios que quedan en pie de la tecnología que permitió a Chile convertirse en el primer país productor de cobre, entre 1851 y 1880.

5. La estación de ferrocarriles de Cachiyuyo: En la Región de Atacama, a $60 \mathrm{~km}$. de Vallenar se encuentra la pequeña localidad de Cachiyuyo. Si bien se han encontrado en sus alrededores vestigios arqueológicos de asentamientos prehispánicos, como vasijas y restos de material lítico, el registro de los primeros habitantes del poblado se relaciona con la función de cobre, oro y plata a fines del siglo XIX, de cuyos tiempos data esa estación férrea.

\section{Fase de Producción}

\section{Etapa I Diseño}

Eldiseño del juego o game design es el proceso de proyectar el contenido, los antecedentes y las reglas de un juego o de cualquier sistema interactivo recreativo. Suele ser aplicado 
principalmente a los ambientes virtuales, aunque se sigue empleando para elaborar juegos fuera del espacio virtual (Martínez Soto, Egea Vivancos, \& Arias Ferrer, 2018). Los elementos principales que contiene el game design de $\mathrm{RH}$ son: Historia, niveles, personajes y habilidades de los personajes.

1. Historia: El videojuego es una obra de formato narrativo por lo tanto es importante su historia, la cual debe crear expectativa en el jugador por un mundo alternativo, motivándolo a seguir jugando para descubrir la culminación de los diversos sucesos que componen la historia. $\mathrm{RH}$ fue inspirado en el "viaje del héroe", el viaje del héroe o monomito, es un término acuñado por el antropólogo y mitólogo estadounidense Joseph Campbell para definir el modelo básico de muchos relatos épicos de todo el mundo. A continuación se describe la historia introductoria de RH.

El chamán oscuro despierta y crea a los Golems elementales quienes se han robado el patrimonio de Atacama. Sí no es recuperado se perderán las raíces históricas. Los habitantes animales y humanos de Atacama no tendrán identidad, caerán bajo la magia oscura del chaman. El espíritu de Yastay (protector de los animales de los cerros) cada cierto tiempo renace en la forma de un animal, en esta generación ha nacido en el cuerpo de un zorro Culpeo, sin embargo nuestro personaje aun joven y miedoso, no ha despertado el espíritu de Yastay que está dentro de él. Para lograrlo tiene que pasar por distintas pruebas y vencer a los Golems elementales. Es así como los animales protectores de Culpeo, el aguilucho y la chinchilla van en su desesperada búsqueda para que enfrente al chamán oscuro y logre salvar la identidad patrimonial de Atacama, y así a toda su población.

\section{Niveles}

En su primera versión, RH posee 5 niveles, en cada nivel hay un patrimonio cultural que rescatar, tiene una duración de 10 minutos por nivel. En su versión final, el videojuego constará de 15 niveles de juego, abarcando así, casi la totalidad de los inmuebles declarados monumentos históricos en la región (Chile, Leychile, 1925). El juego tendrá una duración de 150 minutos, es decir 2.5 horas. Cada nivel posee mecánicas distintas y únicas dentro del juego como se resume en la Tabla 2.

Tabla 2. Mecánicas por niveles.

\begin{tabular}{cc}
\hline Niveles & \multicolumn{1}{c}{ Mecánicas } \\
\hline Nivel 1 & Plataformas con movimiento (arriba-abajo, derecha-izquierda) \\
Nivel 3 & Earedes con movimiento que hacen daño \\
Nivel 4 & Zonas con contaminación hacen daño constante \\
Nivel 5 & Carros de tren dificultan el avance generando daño
\end{tabular}


Cada mecánica de nivel tiene un patrimonio a rescatar, además de los elementos del juego como: cajas movibles que sirven para alcanzar puntos lejanos, diamantes que otorgan puntos, cada 100 puntos se recupera una vida, trampas de pinchos que quitan vida, entre otros. En las figuras 2 hasta la 8 se muestran las mecánicas junto a los elementos de algunos de los niveles.

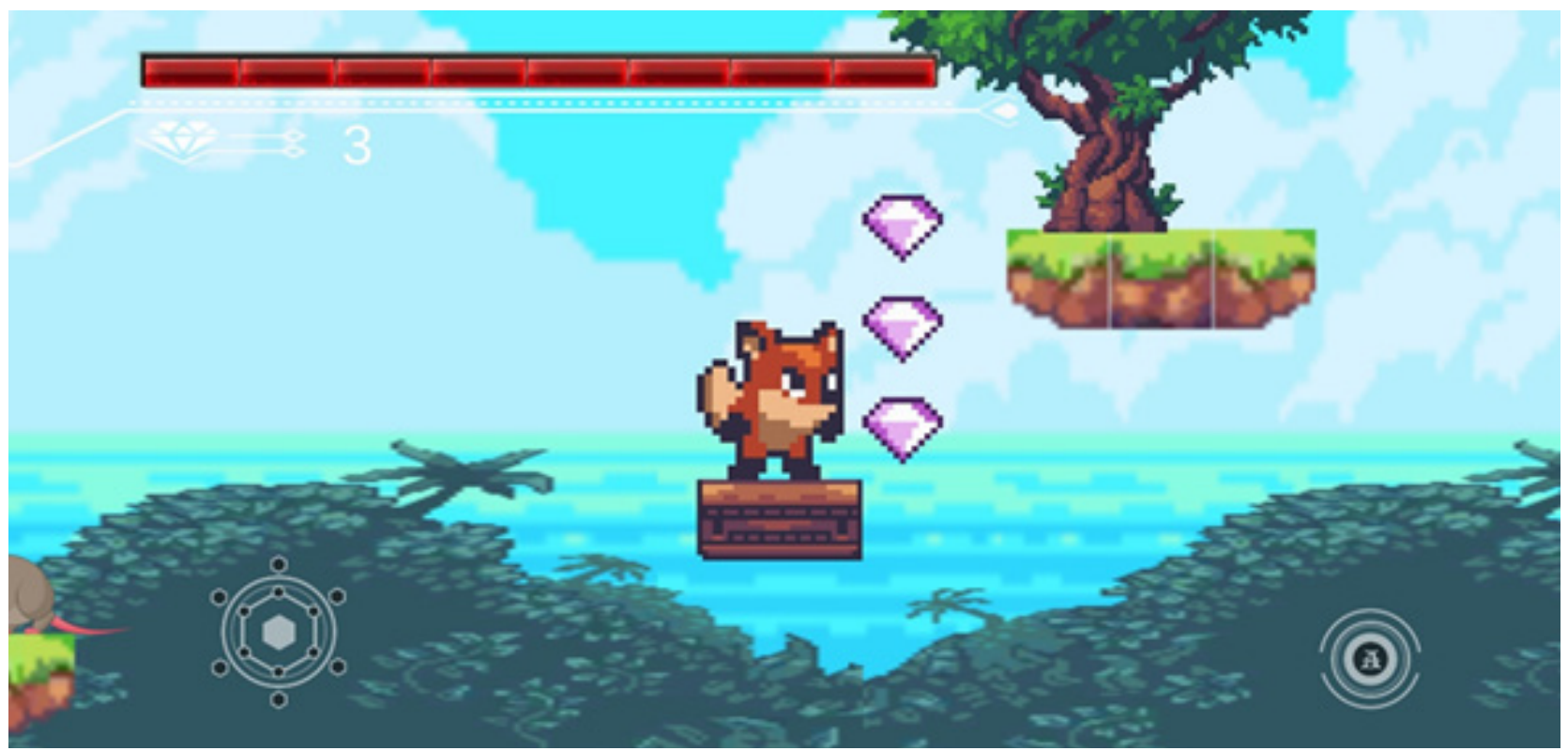

Figura 2. Mecánica del nivel 1.

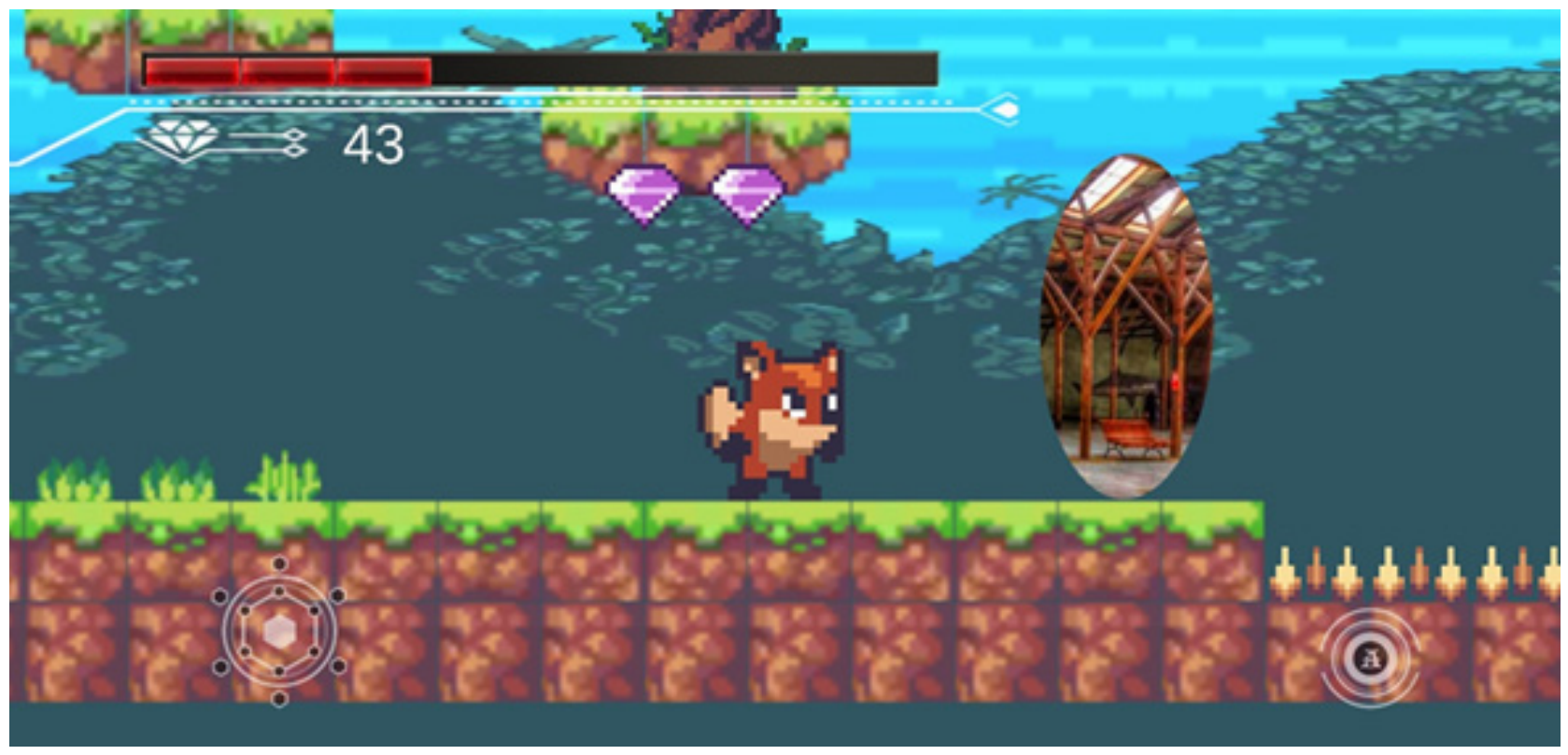

Figura 3. Culpeo encontrando la estación de Caldera en el nivel 1. 


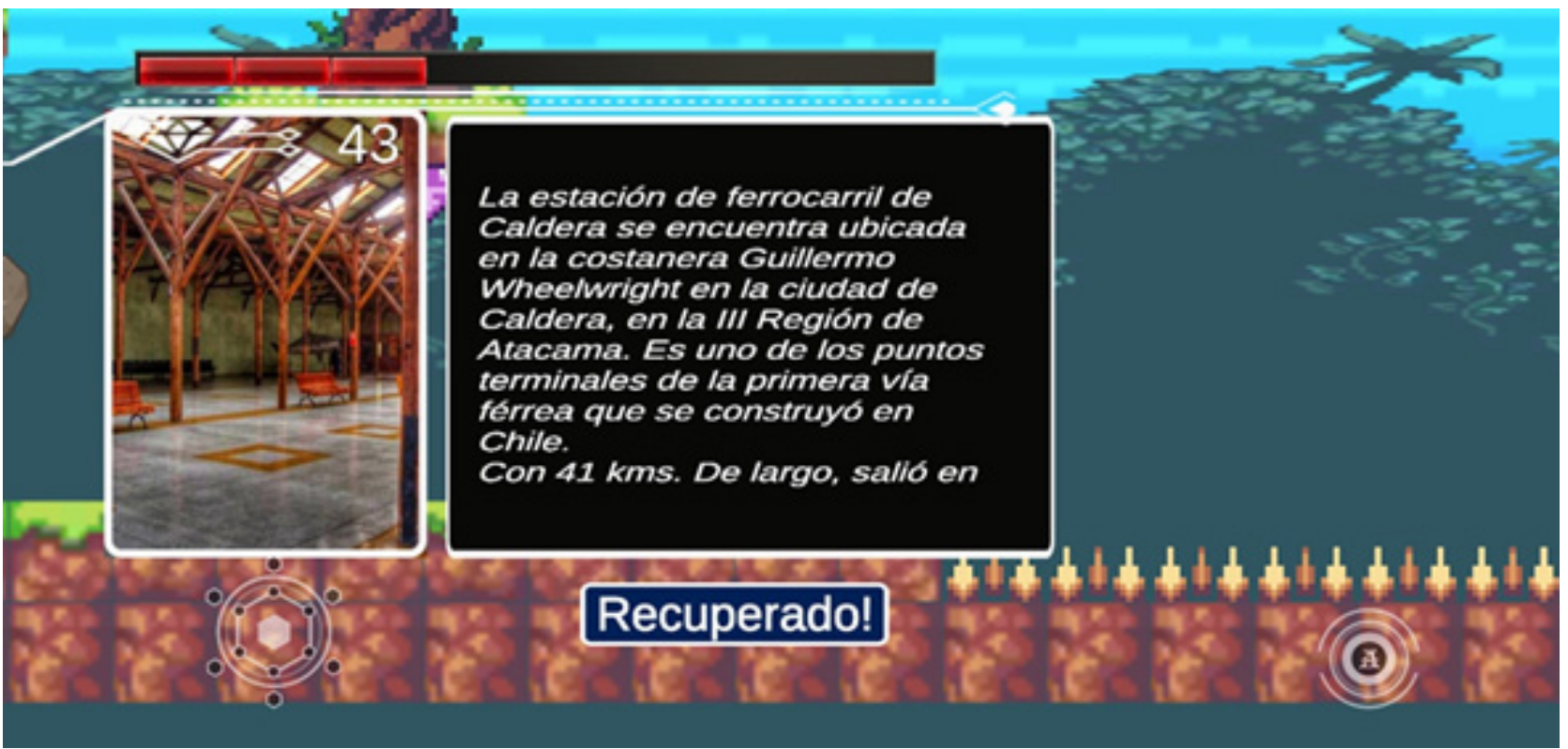

Figura 4. Patrimonio estación de ferrocarril de Caldera, recuperado del nivel 1.

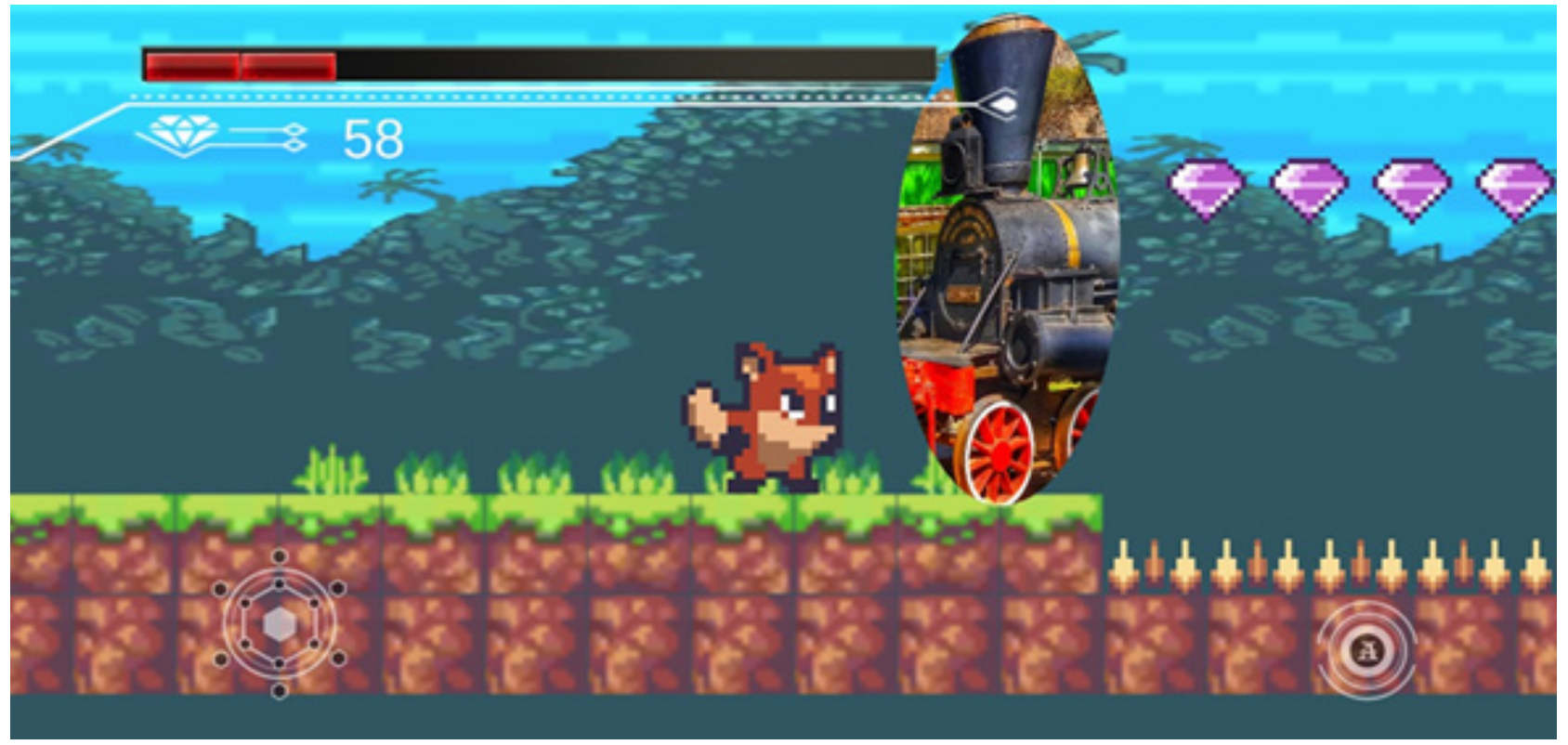

Figura 5. Culpeo encontrando la locomotora "Copiapó" en el nivel 2 


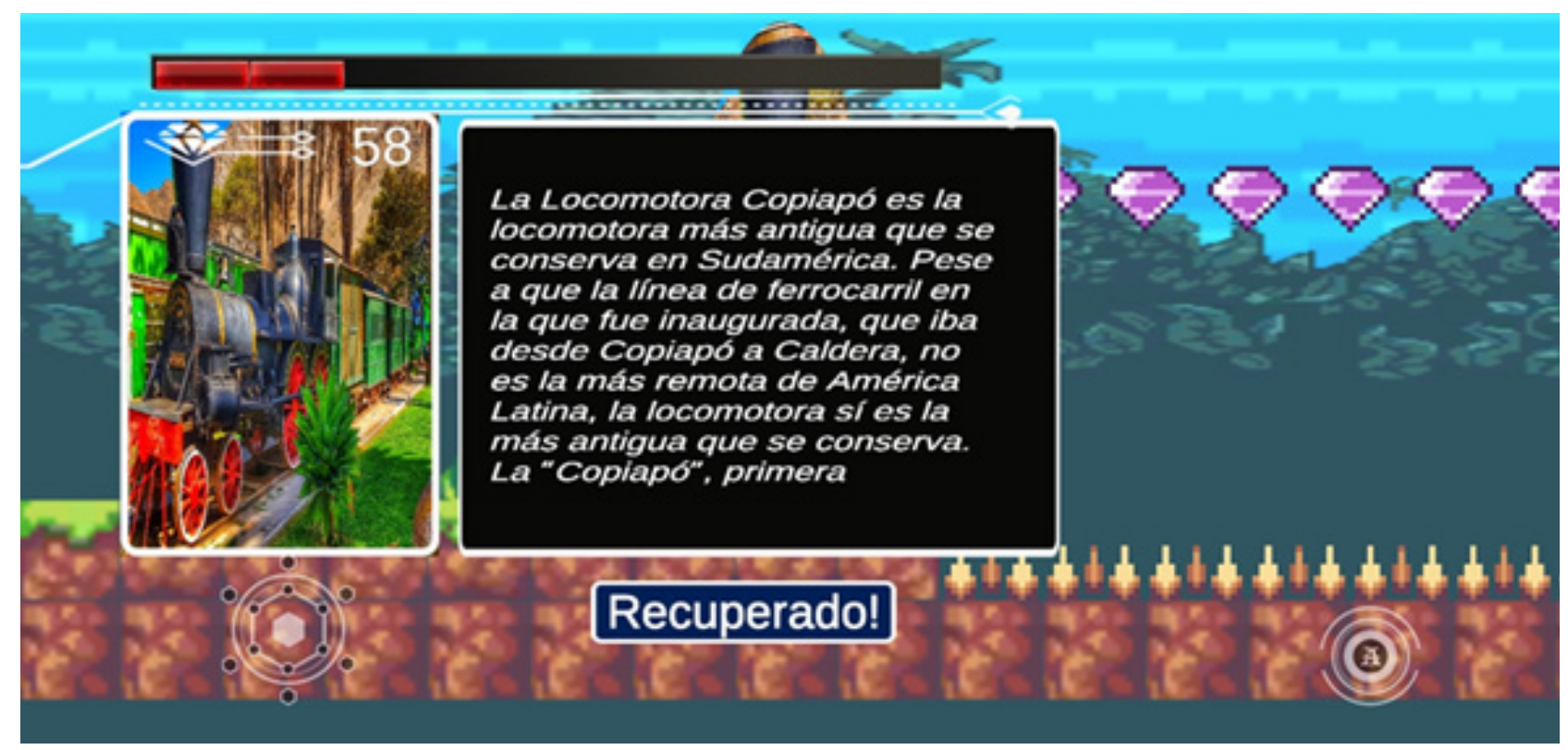

Figura 6. Locomotora "Copiapó" recuperada en el nivel 2.

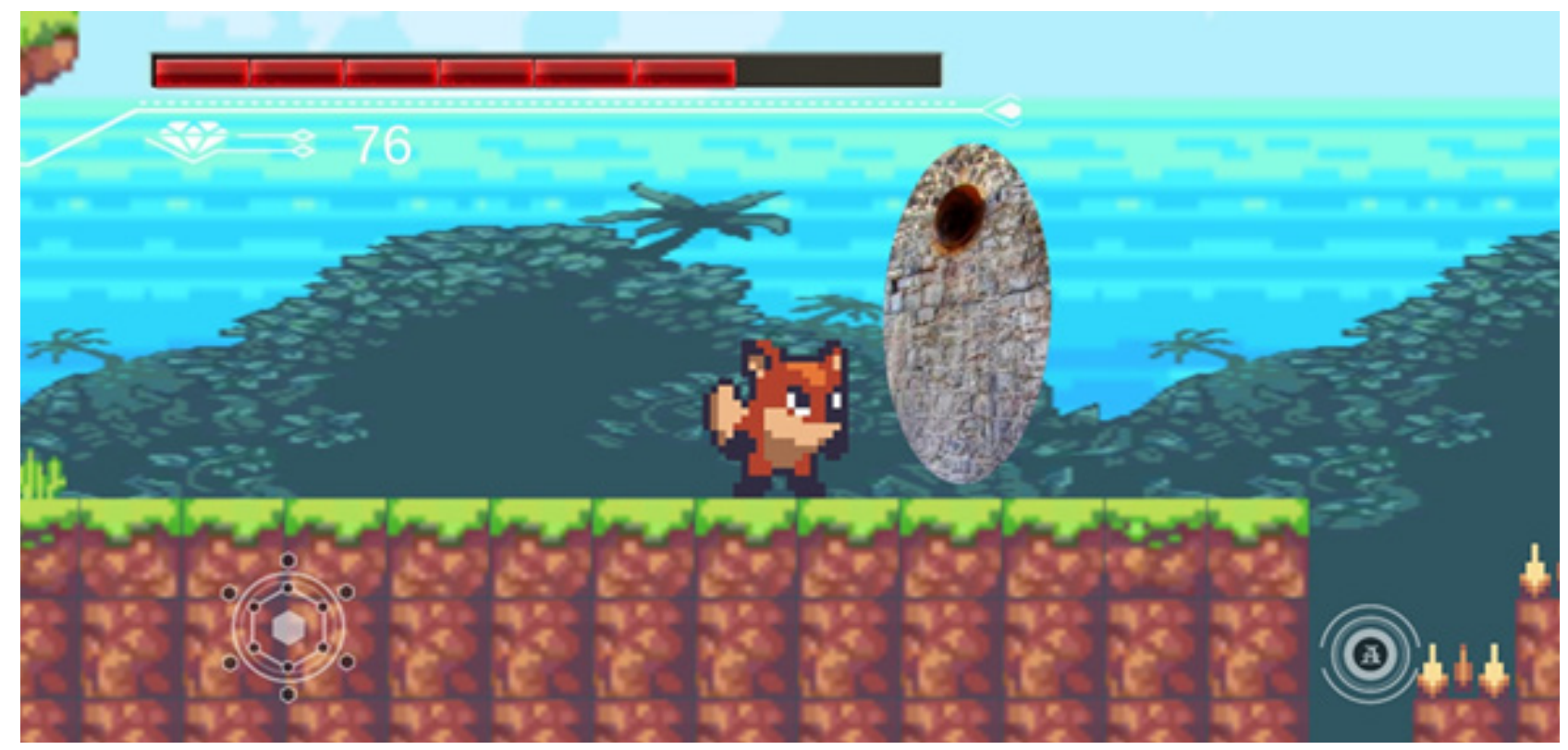

Figura 7. Culpeo encontrando las chimeneas de labrar en el nivel 4. 


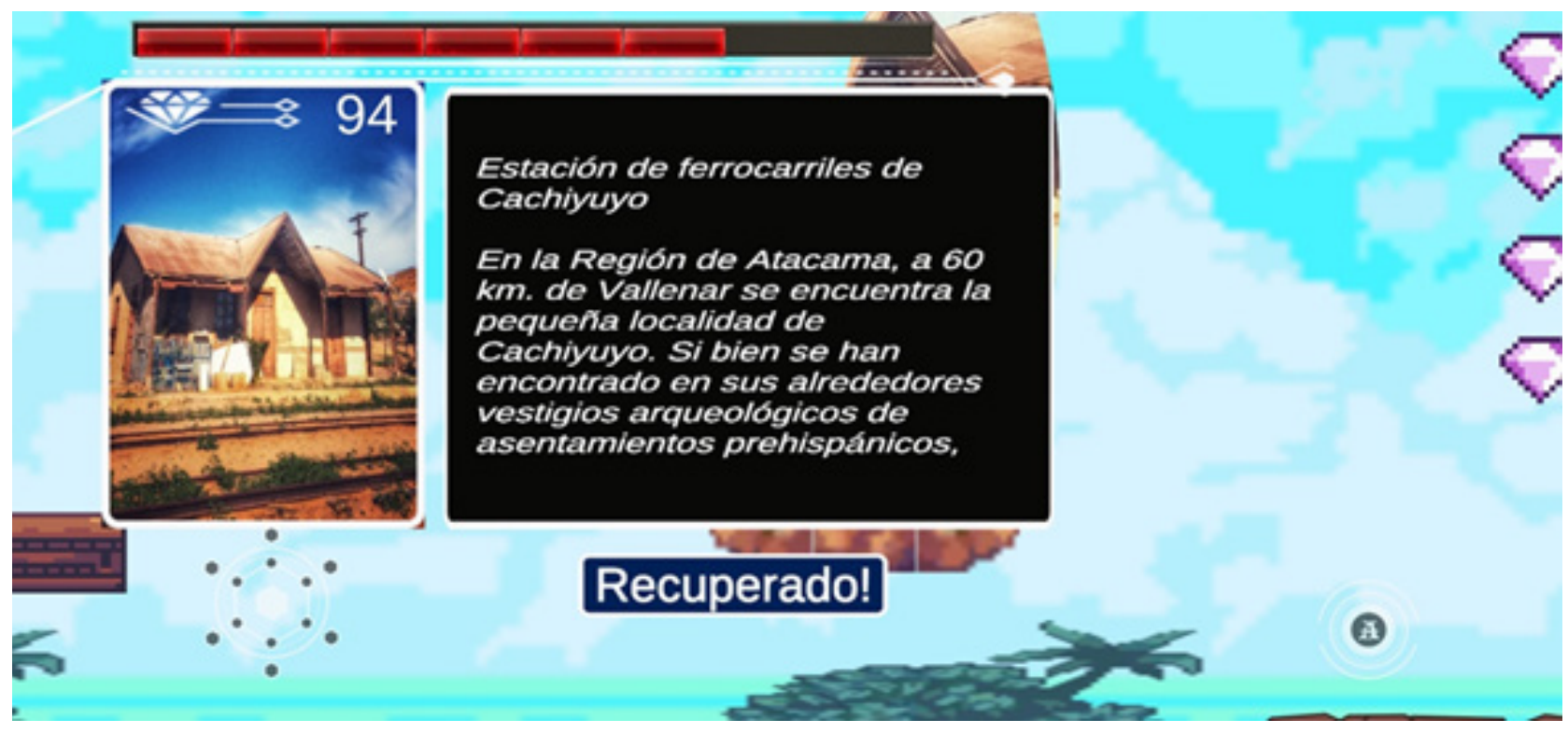

Figura 8. Estación de Cachiyuyo recuperado en el nivel 5.

\section{Personajes}

Los personajes están inspirados en la fauna nativa de la región de Atacama, así como personajes mitológicos de los pueblos originarios de la zona. A continuación se dará una breve descripción de cada uno.

Personaje principal: es representado por un zorro Culpeo, ver Figura 9a, llamado de la misma forma "Culpeo" el cual contiene el espíritu de Yastay. Para despertar el espíritu de Yastay debe pasar por distintas pruebas y derrotar a sus enemigos, cada vez que tenga una victoria obtendrá una nueva habilidad elemental hasta que logre despertar a Yastay para vencer a su enemigo final.

Personajes secundarios: amigos del personaje principal Culpeo, estos son: la
Chinchilla y el Aguilucho Ver Figura 9b quienes conocen de la profecía y su misión es encontrar a Culpeo convencerlo de su aventura y apoyarlo hasta que este alcance su objetivo.

Enemigos: los enemigos son Golems elementales (agua, polvo, smog y microorganismos) son los elementos presentes en la atmósfera que causan daño a los monumentos con el tiempo. Los Golems pueden ser de dos tipos el Golem Lanzador Figura 9.c y el Golem Destructor Figura 9.d, quien se encuentra custodiando el patrimonio robado.

Enemigo final: Es el Chamán oscuro Figura 9.f, entre sus habilidades está la de convocar a los Golems elementales y la magia oscura. 


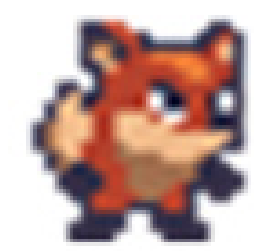

(a)

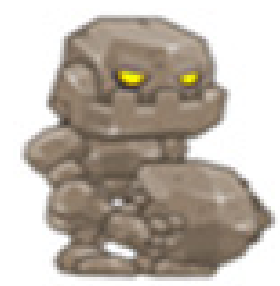

(c)
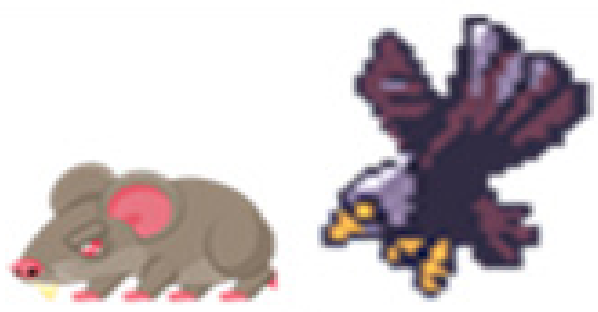

(b)

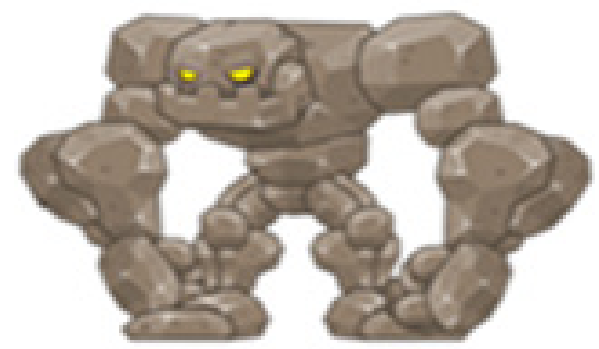

(d)

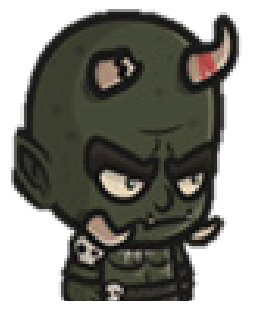

Figura 9. Personajes.

En la figura10 se observa el enfrentamiento entre Culpeo y el Golem.

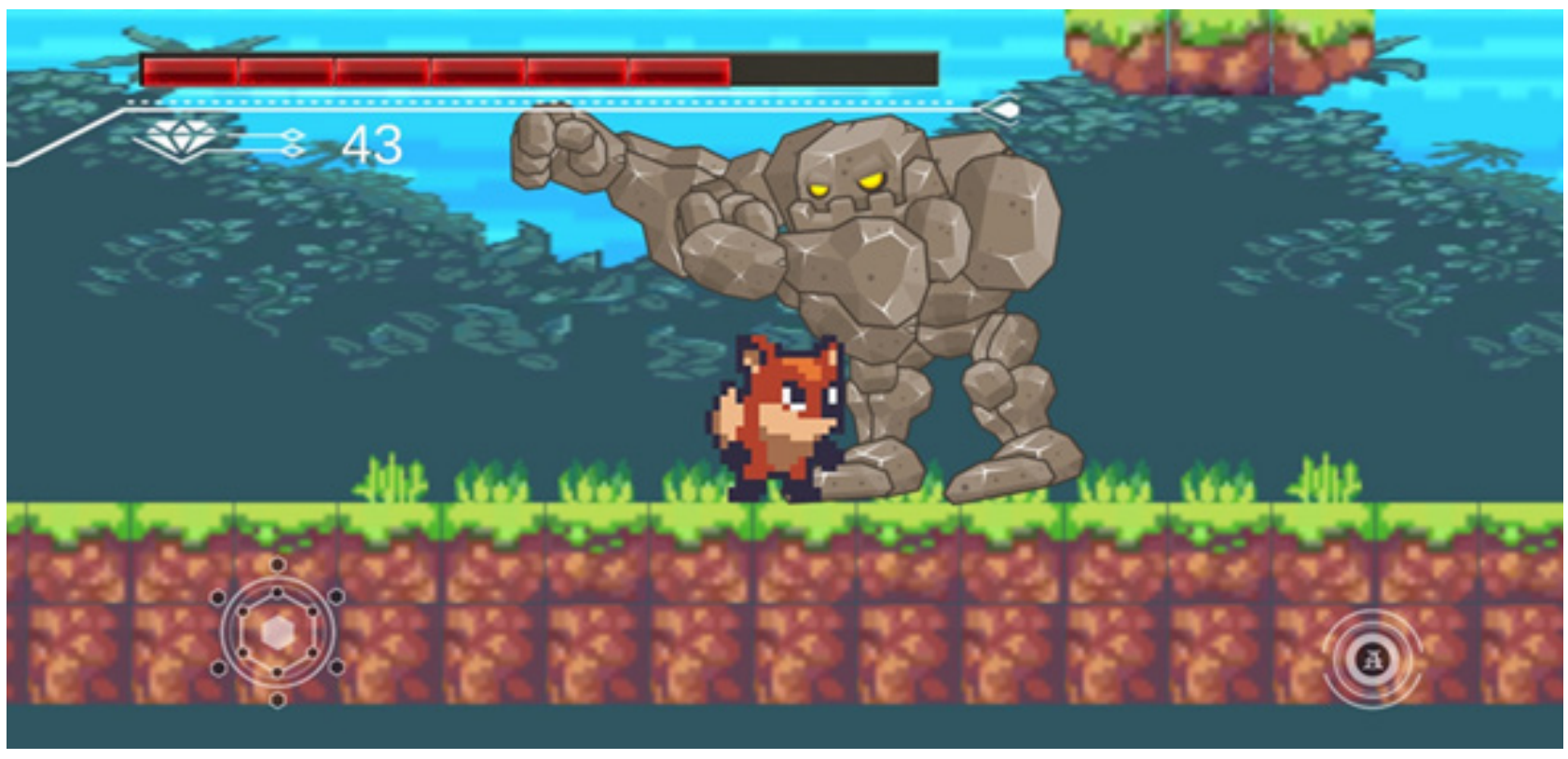

Figura 10. Culpeo y su enfrentamiento con el Golem.

4. Habilidades de los personajes: los personajes poseen ciertas habilidades Culpeo es quien posee mayor cantidad de habilidades que el jugador debe ir desbloqueando en cada nivel. La tabla 2 resume las habilidades. 
Tabla 3. Habilidades y personajes.

\begin{tabular}{|c|c|}
\hline Personaje & Habilidades \\
\hline Culpeo & $\begin{array}{l}\text { - } \quad \text { Salto: hace daño a sus enemigos al saltar sobre ellos. } \\
\text { - } \quad \text { Esfera de agua: habilidad desbloqueada, arroja una esfera de agua a distancia. } \\
\text { - Remolino de polvo: habilidad desbloqueada genera un remolino con una cierta cantidad de } \\
\text { - } \quad \text { Niempo. } \\
\text { - } \quad \text { Microorar habilidad desbloqueada, paraliza al enemigo por una cantidad de tiempo. } \\
\text { - Poder de Yastay: maneja todas las habilidades y genera un rayo de sol Culpeo recupera vida } \\
\text { al estar bajo el rayo. }\end{array}$ \\
\hline Golem lanzarocas & Sigue un patrón de patrullaje detecta al personaje y lanza rocas para dañarlo. \\
\hline Golem & Enemigo final por nivel, ataca con sus puños y se mueve con un patrón. \\
\hline Chamán oscuro & Enemigo final juego, convoca Golems y arroja esfera de oscuridad. \\
\hline
\end{tabular}

\section{Etapa II: Diseño Técnico}

El desarrollo de un videojuego consiste en la integración de elementos que lo constituyen en un software que permita el diseño, creación y representación del videojuego (Graells, 2013). Para el desarrollo de RH se optó por utilizar: (a) el Software Unity, (b) el C\# de Microsoft como lenguaje de programación, (c) el Animation para crear la animación a través de la unión de sprites y (d) el Animator para unir todas las animaciones de un personaje a través de distintas lógicas y programadas a través del lenguaje C\# como se muestra en la figura 9. De estas animaciones destacamos el estado Idle, el cual consiste en una animación que presenta al personaje en reposo, donde se da la sensación que este respira y observa su entorno. Así mismo existen otros estados de movimiento como, giro, caminar, saltar, entre otros. Estos estados se utilizan para darle mayor naturalidad de movimiento al personaje dentro del videojuego.

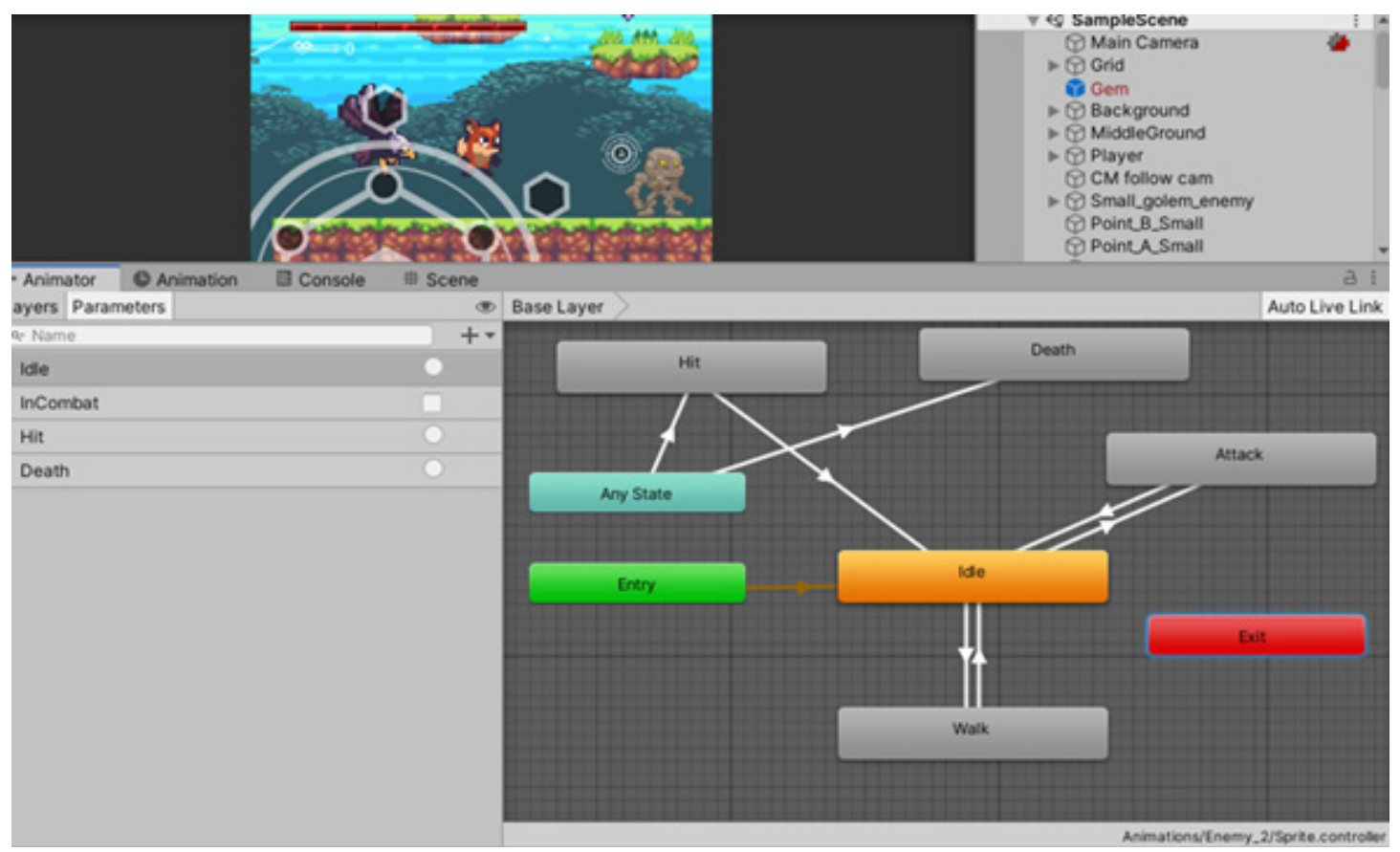

Figura 11. Controlador de animaciones. 
Los elementos de animación y objetos del nivelinteractúan a través de eventosestructurados y programados. La unión y creación de todos estos elementos dan como resultado el nivel de interacción o mundo del juego, estos son creados a través de escenas dentro de Unity. Finalmente la unión y programación de estas escenas da como producto final el videojuego.

\section{Etapa III: Implementación}

La etapa de implementación permite organizar de manera coherente todas y cada una de las piezas producidas y planificadas hasta el momento Se genera un engranaje que funciona con el motor gráfico (Unity). Es un proceso en el cual se revisan y se perfilan los detalles, se corrigen errores y a la vez se depuran ideas que no estén relacionadas con la temática del juego. Una vez que se mezcla lo técnico, artístico y mecánico, el producto está listo para probarlo.

\section{Etapa IV: Pruebas}

Las pruebas permiten verificar la eficacia de cada elemento del juego, su funcionamiento y el resultado final. Las pruebas son de dos tipos: pruebas alpha y pruebas beta descritas a continuación.

\section{Pruebas Alpha}

Las pruebas alpha del juego RH se realizan cuando el desarrollador considera que ya tiene el producto final. Consiste en un testeo previo antes de dar por concluido el proyecto. El producto se revisa buscando errores o matices que deban ser corregidos, esta prueba la realiza el desarrollador.
Uno de los aspectos fundamentales a revisar es el criterio de jugabilidad. Se realizaron las pruebas de funcionalidad aplicando el functionality testing o FQA.

\section{Pruebas Beta}

En la pruebas beta se dan por concluidas todas las variaciones del contenido (misiones, gráficos, textos, sonidos, entre otras). En este caso las pruebas son realizadas por personas externas al proyecto los cuales redactan un informe donde se registren los fallos encontrados durante la revisión. Estas pruebas se realizan para minimizar los defectos del juego RH. Se realizaron las pruebas relacionada con la experiencia de juego aplicando el playtesting.

Una vez el diseño del juego RH fue aprobado se aplicó

\section{RESULTADOS}

Los resultados de la aplicación del juego en la población de niños se obtuvieron de forma remota debido a la contingencia mundial por la pandemia del Covid-19. Se contó con la autorización y participación activa de los padres de los niños, el videojuego fue descargado e instalado por ellos en sus respectivos dispositivos móviles, posteriormente los niños jugaron y al finalizar recibieron un cuestionario para evaluar la actividad con el videojuego $\mathrm{RH}$.

\section{Criterio de jugabilidad}

Es el grado de competencias que tienen los jugadores en el uso de videojuegos. 


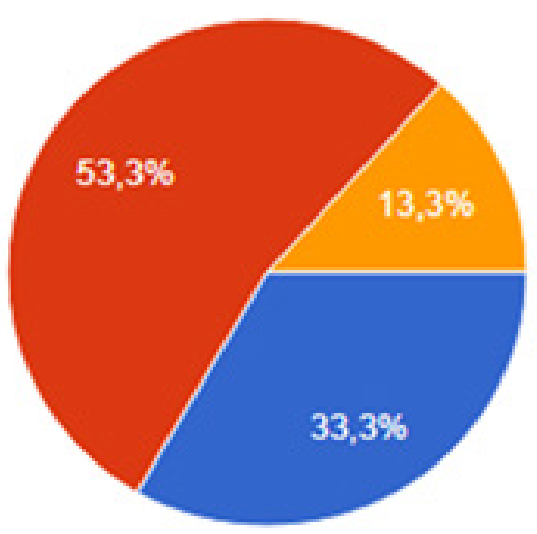

Gráfico 1. Horas dedicadas a jugar por semana.

Los niños que interactuaron con el juego dedican más de 6 horas semanales al uso de videojuegos (53.3\% de 6 a 10 horas y 13,3\%más de 10 horas), declarando que poseen habilidades para jugar videojuegos.
Las habilidades que tiene para el juego y con respecto a la experiencia, los resultados se resumen en la tabla 4.

Tabla 4. Aspecto jugable.

\begin{tabular}{cccccc}
\hline & Nada & Poco & Regular & Bastante & Superior \\
\hline E1 Experiencia en videojuegos & - & - & $33.3 \%$ & $53.3 \%$ & $13.3 \%$ \\
J1 Habilidad de jugador & - & - & $20 \%$ & $46.7 \%$ & $33.3 \%$ \\
\hline
\end{tabular}

El 53.3\% de los participantes reconocen haber jugado algún juego con contenido histórico como se muestra en la Tabla 5.

Tabla 5. Aspecto juegos con contenido histórico.

\begin{tabular}{llll} 
& No & Tal vez & Si \\
\hline J2 videojuegos Históricos & $33.3 \%$ & $13.3 \%$ & $53.3 \%$ \\
\hline
\end{tabular}




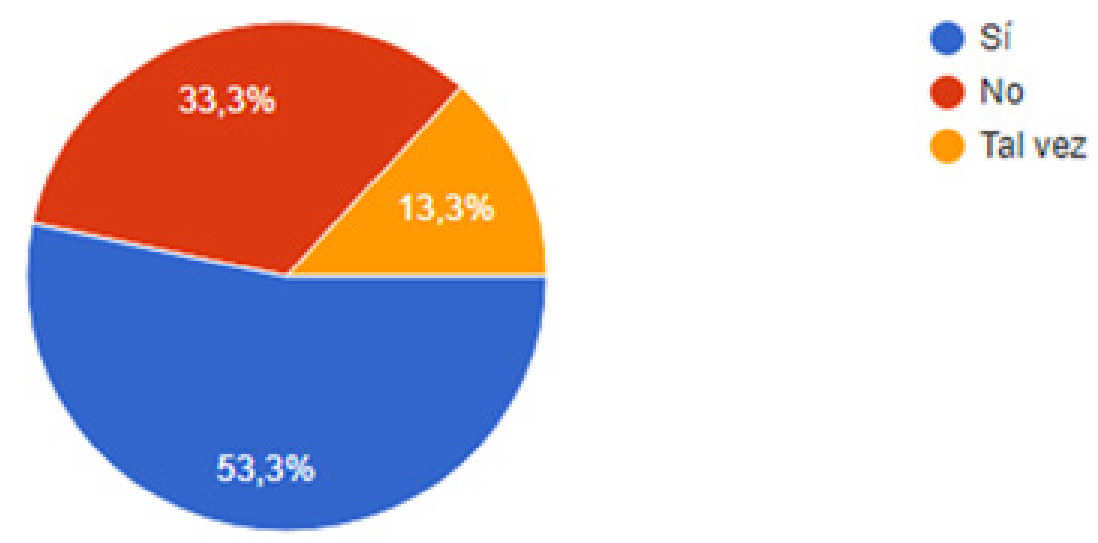

Gráfico 2. Juegos con contenido histórico.

\section{Aspecto Pedagógico}

Los participantes reconocen que la experiencia jugable con $\mathrm{RH}$ les ha ayudado a aprender sobre el patrimonio histórico cultural de la región (86.7\% de aceptación); un 13.3\% pone en duda lo aprendido, no existiendo valoraciones negativas.
Respecto a la percepción de por qué aprendieron con RH, se ilustra en el Gráfico 3, En mayor proporción por sus imágenes $(86,7)$, aprendizaje $(80 \%)$ y ejercitación de la memoria $(73,3 \%)$

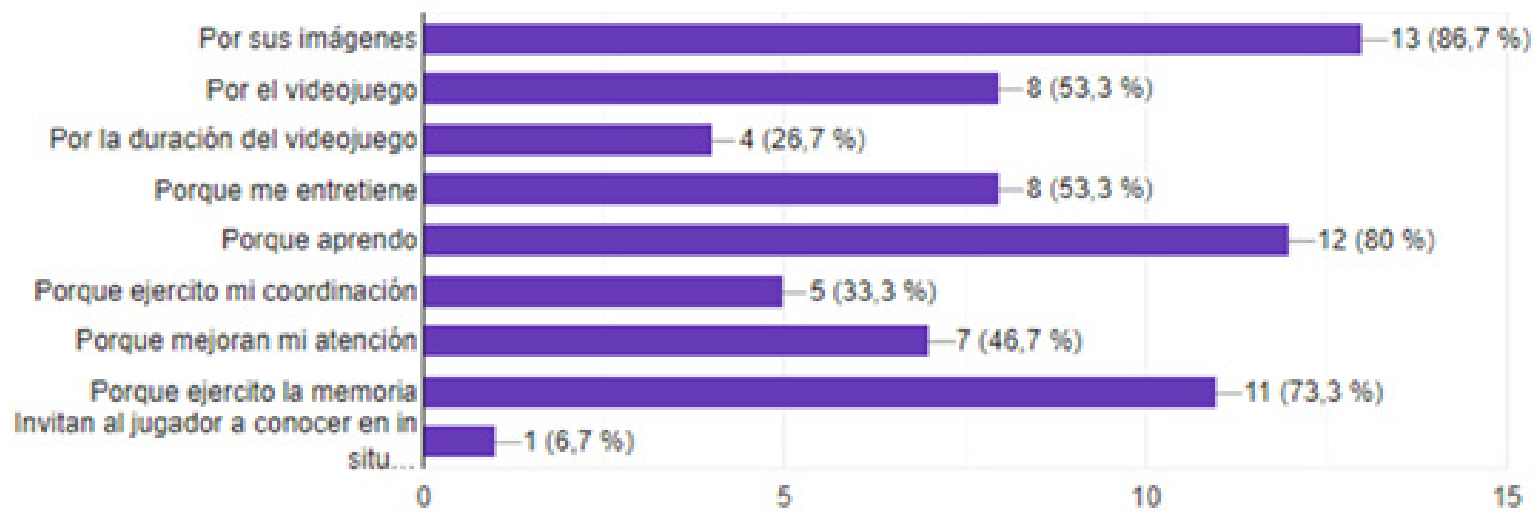

Gráfico 3. Principales características de aprendizaje dentro de RH 


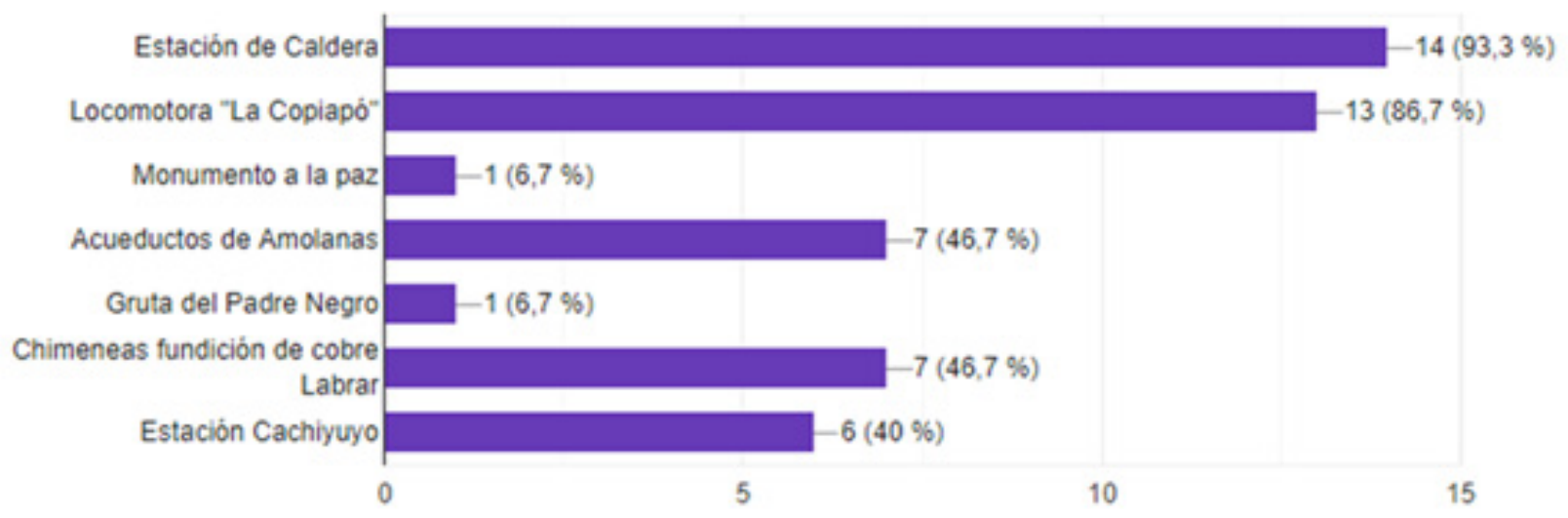

Gráfico 4. Reconocimiento del patrimonio histórico
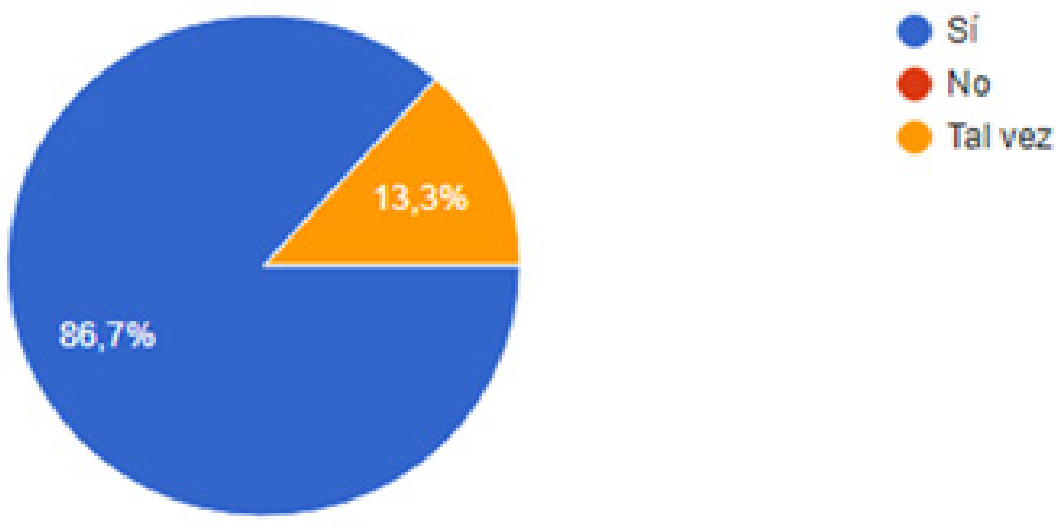

Gráfico 5. Aprendizaje con el juego RH

El objetivo principal de esta investigación era examinar como los participantes aprendían y reconocían los patrimonios seleccionados de una manera más fácil a través de un videojuego educativo.

Uno de los aspectos mejor valorados por los participantes en este estudio piloto ha sido la oportunidad de conocer patrimonios de una forma divertida, inmersiva y activa. En general, el aprendizaje en primera persona es valorado por los participantes, seguramente porque se superan las barreras que la vida real muestra. Además, parece demostrarse la importancia de desarrollar herramientas como los videojuegos, para el propósito de aprendizaje a través de ellos. Cuando se consigue estudiar contenidos históricos de una forma más interactiva, los participantes demuestran un mayor interés.

Sin embargo, el análisis cualitativo de las respuestas abiertas de esta investigación, parece demostrar que es preciso un diseño más meditado de los contenidos a trabajar y reforzar con el juego, así como incorporar más mecánicas y funcionalidades dentro de $\mathrm{RH}$.

Finalmente, luego de tener la experiencia de aprender con $\mathrm{RH}$, los participantes en su mayoría indican que les seria grato estudiar y aprender temas relacionados con patrimonio histórico cultural mediante el uso de un videojuego. 
CONCLUSIONES

El juego RH logra un aprendizaje significativo acerca del patrimonio cultural regional de Atacama, apoyando a un aprendizaje intrínseco como una herramienta innovadora y estimuladora para los niños y jóvenes estudiantes. Al tratarse de un videojuego 2D de plataformas es necesario que el jugador este constantemente tomando decisiones, estas serán vitales para definir la dificultad de las fases del juego, así mismo si es capaz de recolectar todo el patrimonio para poder ganar, el cual entregará la información precisa del monumento. Esta serie de conductas repetidas concluye con el aprendizaje del jugador sobre la sociedad, la cultura y el patrimonio de Atacama. Así mismo, esto ofrece al jugador un aprendizaje que normalmente no experimentaría en la realidad de una actividad pedagógica tradicional.

Los niños y jóvenes de la población en estudio se sienten motivados por tener más actividades de este tipo, donde su concentración se vuelve inmersiva, se divierten y al mismo tiempo aprenden intrínsecamente. Además de dar un argumento positivo para crear más herramientas tecnológicas para apoyar el aprendizaje escolar, donde se les genere mayor motivación por el aprendizaje.

El grado de diversión del videojuego, generará una experiencia educativa en el jugador caracterizada por el intercambio de información y el refuerzo de los contenidos.

Los videojuegos entregan un escenario tecnológico idóneo para que los estudiantes desarrollen habilidades, actitudes y conocimiento de nueva información.

REFERENCIAS

Cheng, C., y Su, C. (2012). A game-based learning system for improving student's learning effectiveness in system analysis course. Procedia-Social and Behavioral Sciences, 31, 669-675
Chile, G. d. (1925). leychile. Retrieved 08 2018, 13, from https://www.leychile.cl/ Navegar?idNorma $=28892$

Consejo de Monumentos Nacionales de Chile (sf)

Cuenca, J.M. y Martín, M. (2010). La resolución de problemas en la enseñanza de las Ciencias Sociales a través de videojuegos. Íber. Didáctica de las Ciencias Sociales, Geografía e Historia, 63, 32-42

DIBAM. (2005). Memoria, cultura y creación. Santiago: Lineamientos políticos

Fondo de Fomento al Arte en la Educación (2018). Consejo de la Cultura. Gobierno de Chile: Autor

Graells, 2013 Graells, P. M. (2013). Impacto de las TIC en la educación: funciones y limitaciones. 3C TIC, 2(1)

Ibáñez, A., Fontal, O. y Cuenca, J.M. (2015). Actualidad $y$ tendencias en Educación Patrimonial. Educatio Siglo XXI, 33(1), 1114

Jiménez-Palacios, R. y Cuenca, J. (2015). El uso didáctico de los videojuegos. Concepciones e ideas de futuros docentes de ciencias sociales. Clio. History and History teaching, 41, 14-58

Martinez Soto, J. M., Egea Vivancos, A., \& Arias Ferrer, L. (2018). Evaluación de un videojuego educativo de contenido histórico. La opinión de los estudiantes. Revista Latinoamericana de Tecnología Educativa, 17(1)

Pagès, J.-Pons, M. (1986) El passat que tenim present: Solsona i el Solsonès" a D.A. Jornades d'Experiències Didàctiques: Ciències Socials al Cicle Superior. Bellaterra: ICE-Universitat Autònoma de Barcelona, pp.109-123

Reig, D. (2012). TIC, TAC y TEP. Sociedad aumentada y aprendizaje. Conferencia en el encuentro de la Organización de Estados Iberoamericanos. Metas Educativas para el 2021

Sánchez, F. y Esnaola, G. (2014). Los videojuegos en la educación. Aularia. Revista digital de comunicación. 3(1), 21-26

Stearns, P., Seixas P. y Wineburg, S. (2000). Knowing, teaching and learning history. New York: New York University Press 
UNESCO (2011). «World Heritage Convention Chile». whc.unesco.org. Web de les publicacions de la UNESCO. <http://upo. unesco.org/bookdetails.asp?id=3815>

UNESCO (1982) mapa UNESCO 1982 web patrimonio de la humanidad 